\title{
IDENTIFICATION OF TEMPORARY SURFACE WATER USING SENTINEL-1 SAR DATA, CASE STUDY: SENTANI FLASH FLOODING, INDONESIA
}

\author{
T. A. Gasica ${ }^{1}$, F. Bioresita ${ }^{1, *}$, A. Murtiyoso ${ }^{2}$ \\ ${ }^{1}$ Dept. of Geomatic Engineering, Institut Teknologi Sepuluh Nopember, Surabaya, Indonesia - (gasicaz21, \\ filsa.bioresita)@gmail.com \\ ${ }^{2}$ Photogrammetry and Geomatics Group, ICube Laboratory UMR 7357, INSA Strasbourg, France - arnadi.murtiyoso@insa- \\ strasbourg.fr
}

Commission III, WG III/1

KEY WORDS: Temporary surface water, Flood, Sentinel-1, Rapid mapping method, SAR polarimetry

\begin{abstract}
:
Temporary surface water monitoring can provide accurate and reliable information about the spatio-temporal level of surface water. This is very important for various environmental applications, such as flood monitoring. Remote sensing data such as Synthetic Aperture Radar (SAR) is very useful for a large-scale flood monitoring. SAR sensors offer clear advantages by providing their own sources of illumination, thus being able to operate in nearly all-weather/day-night conditions. About $30 \%$ disasters which occurred in Indonesia are floods. This hazard has become a recurring disaster that takes place annually. A massive flash flood struck Sentani in the Jayapura Regency in the province of Papua, Indonesia on 16 March 2019, causing 104 deaths. The objective of this work is thus to map temporary surface water (flood) of the Sentani flash flooding event in Indonesia using Sentinel-1 SAR imagery. Sentinel-1 IW GRD and SLC (dual polarimetry) on the event period were used. With two types of Sentinel-1 data, this research produced temporary surface water map using rapid mapping method and SAR polarimetry method. Comparing the results, the similarity of SAR polarimetry method to rapid mapping method is about $39 \%$. Based on reference data, rapid mapping result show better accuracy (82\%) than SAR polarimetry method (62\%). In addition, processing SLC data needs longer time and higher performance than processing GRD data. Thus, for rapid mapping, it is better to use only Sentinel-1 GRD data.
\end{abstract}

\section{INTRODUCTION}

Surface waters are important resources for the biosphere and the anthroposphere. Surface waters preserve diverse habitat, support biodiversity, and provide ecosystem service by controlling nutrient cycles and global carbon. Surface waters are essential for human's everyday life, such as for irrigation, drinking-water and/or the production of energy (power plants, hydroelectricity) (Brönmark and Hansson, 2002; Duker and Bore, 2001; Palmer et al., 2015; Pekel et al., 2014). Temporary Surface Water (TSW) is defined as waterbody experiencing frequent drying phases (small ponds, puddles and wetlands) or correspond to surfaces frequently affected by flooding, thus causing hazards to human, settlements and infrastructures (Feyisa et al., 2014). Floods can be considered as the costliest type of hazard in terms of property damage and fatalities (Martinis, 2010).

About $30 \%$ of the disasters which occurred in Indonesia are floods. This hazard has become a recurring disaster that takes place annually (Sulaeman and Suhartanto, 2017). A massive flash flood struck Sentani in the Jayapura Regency in the province of Papua, Indonesia on 16 March 2019, causing 104 deaths. The flash flooding occurred due to torrential rainfall followed by landslides. On 16 March, a sudden influx of water was observed, which was hypothesized to have originated from the Cyclops Mountains. This was likely caused by a landslide forming a natural dam and therefore blocking the headwaters of a river, which then burst and resulted in the torrential flow. The floodwaters swept away with it significant amounts of material, including uprooted trees and boulders. An increase in the water depth of the local river was reported shortly afterwards, resulting in buildings near the river being inundated. This was probably caused by extensive environmental damage in the Cyclops Mountains.

Remote sensing data can provide information on surface waters. Synthetic Aperture Radar (SAR) as one of active remote sensing is an effective way to detect surface water over large areas. SAR sensors offer clear advantages by providing their own sources of illumination, thus being able to operate in nearly all-weather/day-night conditions. For almost 20 years, spaceborne SAR sensors have increasingly been used for largescale surface water mapping. In 2014, the European Space Agency (ESA) launched the Sentinel constellation including freely available SAR data (Sentinel-1) with high revisiting time (about 12 days) and high spatial resolution (about $20 \mathrm{~m}$ ). This constellation offers the possibility to increase the capture of genuine time series, for example to monitor floods event.

The main goal of this study is thus to map temporary surface water (flood) of the Sentani flash flooding event in Indonesia using Sentinel-1 SAR imagery in GRD and SLC (dual polarimetry) mode. With two types of Sentinel-1 data, this research produced temporary surface water map using rapid mapping method and SAR polarimetry method. The results are then compared.

\section{METHODOLOGY}

\subsection{Study Area}

Sentani is one of the 19 districts in Jayapura Regency and the Capital of Jayapura Regency with an area of $225.90 \mathrm{~km}^{2}$ and a population of 60,531 people in 2011 . This makes the district the most populous one in Jayapura Regency (Pemerintah Provinsi 
Papua, 2006). In March 2019 there was a flash flood that struck this district. The flood caused 104 deaths, 79 people were missing, 160 people were injured, and at least 9,691 people were displaced. Three hundred and seventy five houses were severely damaged, five churches and mosques were seriously damaged, eight schools were heavily damaged and various other damages (Ariansyah, 2019).

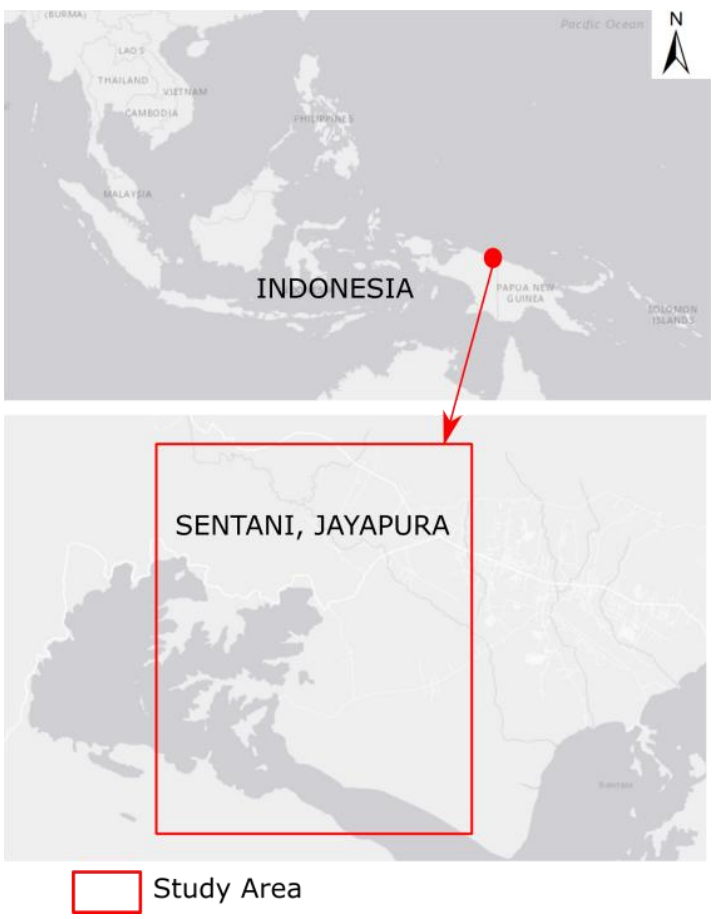

Figure 1. Study area used in this paper.

\subsection{Data}

Two images of Sentinel-1 IW GRDH (Ground Range Detected in High resolution) data and two images of Sentinel-1 IW SLC (Single Look Complex) are available for the study area. Sentinel-1 imageries include images during the event (19/03/2019) and post-event (17/07/2019) collected from the European Space Agency (ESA) Sentinels Scientific Data Hub (ESA, 2019). Each image has a spatial resolution of about $20 \times$ $22 \mathrm{~m}$ with double polarization (VV and $\mathrm{VH})$.

Reference map to assess our results are available through The Charter, a worldwide collaboration, through which satellite data are made available for the benefit of disaster management. The map is produced using Radarsat-2 images (The Charter, 2019).

\subsection{Methods}

As for Sentinel-1 IW GRD, the detection of the surface water and the calculation on the probability of occurrence were carried out with the Water-S1 method presented in a previous research (Bioresita et al., 2018). The method includes preprocessing, tiling approach to focus on water surface areas, class modelling with Finite Mixture Models to produce probability map and bilateral filtering for smooth labelling.

In the tiling approach, images were automatically tiled into rectangular non-overlapping blocks. Then the tile selection is performed to choose only image tiles, which contain some portion of surface waters. The selection is based on Hartigan's dip statistic (HDS) value (Freeman and Dale, 2013).
For class modelling, the Expectation-Maximization (EM) is used to model the parameters of the probability distributions, which contributed to the Finite Mixture Models (Benaglia et al., 2009). The initial means are determined automatically from the binned histograms and the standard deviation is set as 3 for the respective tile. The probability of surface waters is set as 0.1 in accordance with previous works (Bazi et al., 2007; Martinis et al., 2009), suggesting that a minimum amount of $10 \%$ of each class is enough for accurate threshold detection. The EM-based distribution fitting is performed over a maximum of 1000 iterations and tiles for which convergence is not reached within this number of iterations are excluded only for the calculation of the threshold value. Instead of directly determining the threshold value, this process is used to compute posterior probabilities to generate surface water probability maps.

Bilateral filtering is used as a strategy for smooth labelling (Schindler, 2012). The intensity value at each pixel in an image is replaced by a weighted average of intensity values from nearby pixels. The resulting image is subsequently transformed into a binary image assigning all pixels with a probability of surface water greater than 0.9 as water surface.

As for Sentinel-1 IW SLC, SAR polarimetry method was conducted. The first one is an H/Alpha dual decomposition and the second one is H-Alpha dual classification. To perform H/Alpha dual decomposition or H-Alpha dual classification, pre-processing steps including debursting, applying of orbit file and polarimetric speckle filtering were conducted. Polarimetric decomposition allows the separation of different scattering contributions and can be used to extract information about the scattering process. For H-Alpha dual classification, Wishart classifier for unsupervised classification was used. The unsupervised Wishart classification separates data into nine clusters corresponding to nine classes of different scattering mechanisms, using the zones defined in the H/Alpha plane. The Wishart classification will continue to compute the centres of the nine clusters, then reclassify the pixels based on their Wishart distances to cluster centres. This procedure was repeated several times until the user defined total number of iterations is reached (Lee et al., 2004).

Temporary surface water is obtained by subtracting the surface water extraction results between during and post flood event imagery. The accuracy of results is assessed by calculating classical measures (overall accuracy, F-measure (van Rijsbergen, 1979), true positive rates, false positive rates, omission, and commission errors) obtained by a comparison with The Charter product (The Charter, 2019).

\section{RESULTS}

In this study, two experiments of SAR polarimetry method were conducted. The first experiment explores features extracted from decomposition process (H/Alpha dual decomposition). The second experiment performs classification using those features (H-Alpha dual classification).

Polarimetric decomposition allows the separation of different scattering contributions. Using dual polarimetric data, only H/Alpha dual decomposition can be performed in the SNAP software (Sentinel Application Platform). This process is carried out after pre-processing steps. The entropy, anisotropy, and alpha images are the features resulted from this process after terrain correction (Figure 2). Unfortunately, in this study, those images can not provide separation of surface waters from the other land cover type. We can see some patterns with blue 
colour in Entropy and Alpha images, also some patterns with red and yellow colours in Anisotropy image, which represent surface water. However, those patterns and colours can not clearly classify surface water. Thus, in this study we did not continue to explore the results from H/Alpha dual decomposition.

The results (Figure 3) indicated that H-Alpha dual classification successfully extracted some temporary surface water area from Sentinel-1 SLC data. However, the similarity of H-Alpha dual classification result to rapid mapping result is about $39 \%$.
In order to assess the results, both from H-Alpha dual classification and rapid mapping, quantitative evaluation by calculating overall accuracy, F-measure, true positive rates, false positive rates, omission, and commission errors obtained by a comparison with The Charter product. The result from rapid mapping of Sentinel-1 GRD has better assessment (see Table 1) than the result from H-Alpha dual classification of Sentinel-1 SLC. Overall accuracy of rapid mapping is $82.65 \%$ while the result from $\mathrm{H}$-Alpha dual classification generated a value of $62.04 \%$. F-measure value of rapid mapping is 0.81 while from H-Alpha dual classification the value is 0.36 .

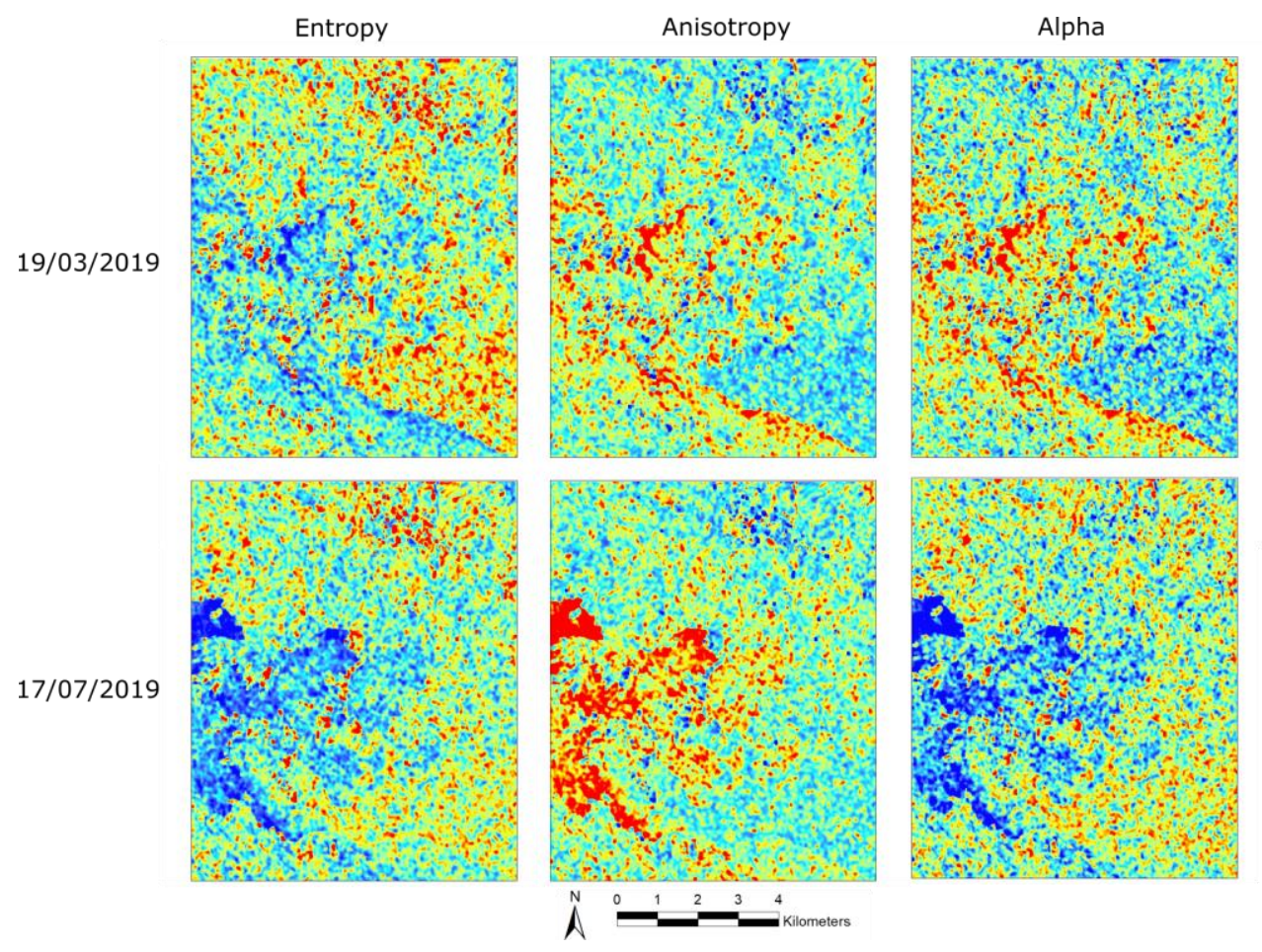

Figure 2. H/Alpha dual decomposition results

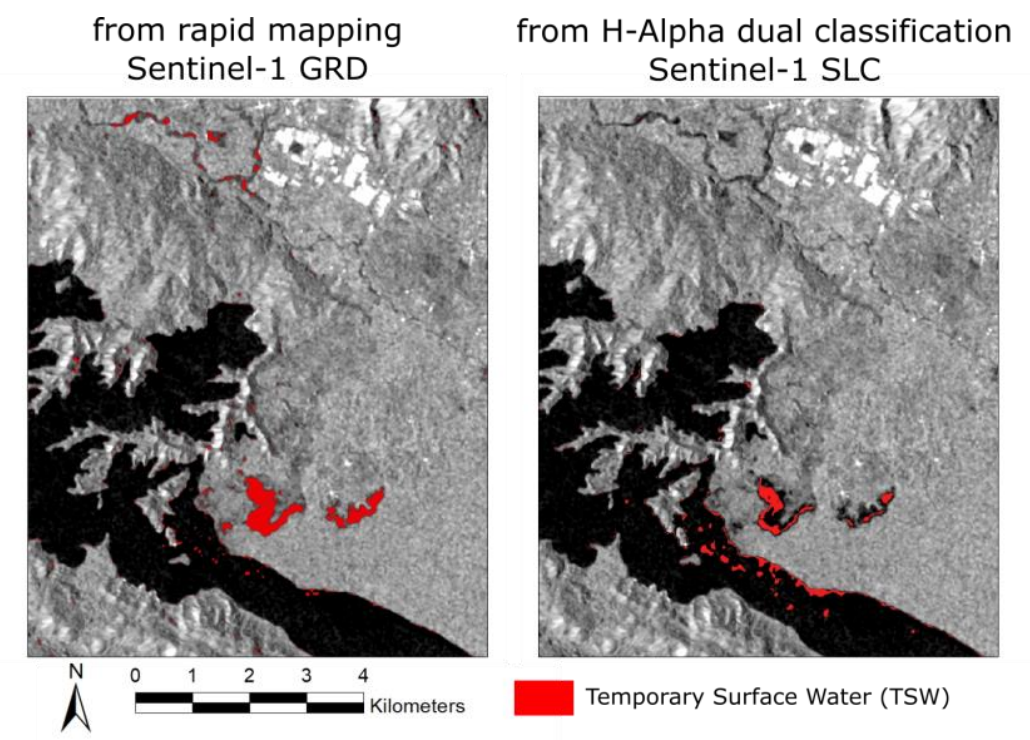

Figure 3. Temporary Surface Water (TSW) results from rapid mapping of Sentinel-1 GRD and from H-Alpha dual classification of Sentinel-1 SLC. 


\begin{tabular}{|c|c|c|c|c|c|c|}
\hline Results & $\begin{array}{c}\text { Overall } \\
\text { Accuracy }\end{array}$ & F-measure & $\begin{array}{c}\text { True Positive } \\
\text { Rate }\end{array}$ & $\begin{array}{c}\text { False Positive } \\
\text { Rate }\end{array}$ & $\begin{array}{c}\text { Omission } \\
\text { error }\end{array}$ & $\begin{array}{c}\text { Commission } \\
\text { error }\end{array}$ \\
\hline $\begin{array}{c}\text { TSW from } \\
\text { Sentinel-1 GRD } \\
\text { (Rapid Mapping) }\end{array}$ & $82.65 \%$ & 0.81 & $74.23 \%$ & $0.09 \%$ & $25.77 \%$ & $11.11 \%$ \\
$\begin{array}{c}\text { TSW from } \\
\text { Sentinel-1 SLC } \\
\text { (H-Alpha Dual } \\
\text { Classification) }\end{array}$ & $62.04 \%$ & 0.36 & $24.59 \%$ & $0.08 \%$ & $75.41 \%$ & $28.57 \%$ \\
\hline
\end{tabular}

Table 1. Quantitative evaluation of temporary surface water results from rapid mapping and H-Alpha Dual Classification

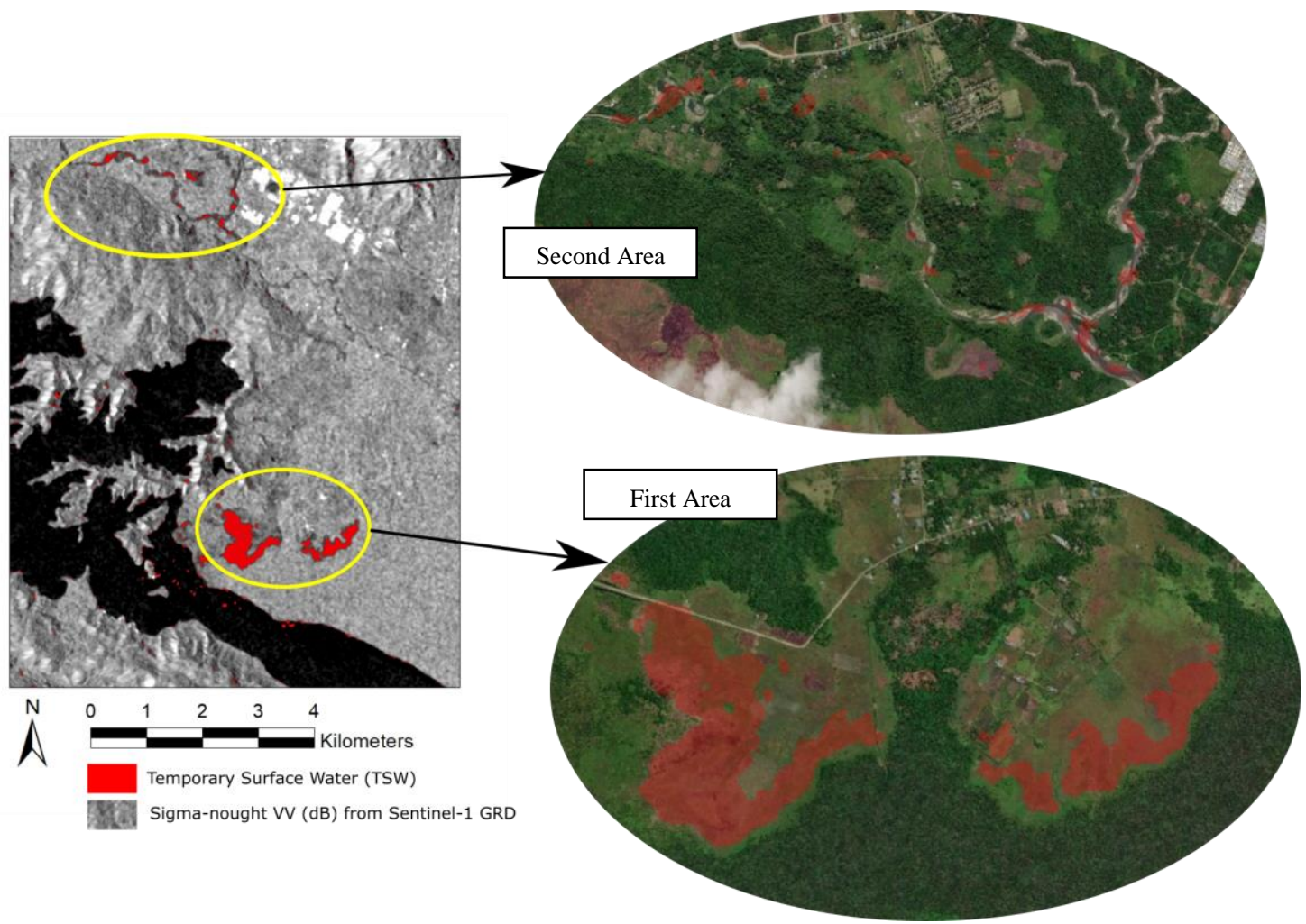

Figure 4. Observation in Temporary Surface Water (TSW) results from rapid mapping of Sentinel-1 GRD

Due to rapid mapping showing better results than the H-Alpha dual classification, as a final result in this study, rapid mapping results will be used and observed. Based on Figure 4, it can be seen that temporary surface water is detected mostly in two areas. Water inundated savanna and swamp forest in the first area, while in the second area, temporary surface water is detected in the riverbank (along the Cyclops mountain river) next to urban area.

\section{CONCLUSION}

In this research, three methods were performed. The entropy, anisotropy, and alpha images resulted from H/Alpha dual decomposition method could not delineate surface water area. H-Alpha dual classification method successfully extracted some temporary surface water area from Sentinel-1 SLC data, however, the similarity of that result to rapid mapping result is only about $39 \%$. Based on quantitative evaluation result, rapid mapping of Sentinel-1 GRD result has better assessment than the result from H-Alpha dual classification of Sentinel-1 SLC. In addition, processing SLC data needs longer time and higher performance than processing GRD data. Thus, for flood mapping in this study, it is better to use only Sentinel-1 GRD data. The results from this research are encouraging for rapid flood mapping and the first step for disaster management.

\section{REFERENCES}

Ariansyah, A., 2019. Update Bencana Banjir Bandang Sentani Provinsi Papua. BNPB. URL https://bnpb.go.id/berita/updatebencana-banjir-bandang-sentani-provinsi-papua (accessed 4.30.20). 
Bazi, Y., Bruzzone, L., Melgani, F., 2007. Image thresholding based on the EM algorithm and the generalized Gaussian distribution. Pattern Recognit. 40, 619-634. https://doi.org/10.1016/j.patcog.2006.05.006

Benaglia, T., Chauveau, D., Hunter, D., Young, D., 2009. mixtools: An R package for analyzing finite mixture models. $J$. Stat. Softw. 32, 1-29.

Bioresita, F., Puissant, A., Stumpf, A., Malet, J.-P., 2018. A Method for Automatic and Rapid Mapping of Water Surfaces from Sentinel-1 Imagery. Remote Sens. 10, 217. https://doi.org/10.3390/rs10020217

Brönmark, C., Hansson, L.-A., 2002. Environmental issues in lakes and ponds: current state and perspectives. Environ. Conserv. 29, 290-306.

Duker, L., Bore, L., 2001. Biodiversity conservation of the world's lakes: A preliminary framework for identifying priorities, LakeNet Report Series. Anapolis, Maryland US.

ESA, 2019. Copernicus Open Access Hub. Copernic. Open Access Hub. URL https://scihub.copernicus.eu/dhus/\#/home (accessed 11.15.20).

Feyisa, G.L., Meilby, H., Fensholt, R., Proud, S.R., 2014. Automated Water Extraction Index: A new technique for surface water mapping using Landsat imagery. Remote Sens. Environ. 140, 23-35. https://doi.org/10.1016/j.rse.2013.08.029

Freeman, J.B., Dale, R., 2013. Assessing bimodality to detect the presence of a dual cognitive process. Behav. Res. Methods 45, 83-97. https://doi.org/10.3758/s13428-012-0225-x

Lee, J.-S., Grunes, M.R., Pottier, E., Ferro-Famil, L., 2004. Unsupervised terrain classification preserving polarimetric scattering characteristics. IEEE Trans. Geosci. Remote Sens. 42, 722-731. https://doi.org/10.1109/TGRS.2003.819883
Martinis, S., 2010. Automatic near real-time flood detection in high resolution X-band synthetic aperture radar satellite data using context-based classification on irregular graphs. $\mathrm{PhD}$ thesis, Fakultät für Geowissenschaften, Ludwig-MaximiliansUniversität München, Germany.

Martinis, S., Twele, A., Voigt, S., 2009. Towards operational near real-time flood detection using a split-based automatic thresholding procedure on high resolution TerraSAR-X data Nat. Hazards Earth Syst. Sci. 9, 303-314.

Palmer, S.C.J., Kutser, T., Hunter, P.D., 2015. Remote sensing of inland waters: Challenges, progress and future directions. Remote Sens. Environ. 157, 1-8. https://doi.org/10.1016/j.rse.2014.09.021

Pekel, J.-F., Vancutsem, C., Bastin, L., Clerici, M., Vanbogaert, E., Bartholomé, E., Defourny, P., 2014. A near real-time water surface detection method based on HSV transformation of MODIS multi-spectral time series data. Remote Sens. Environ. 140, 704-716. https://doi.org/10.1016/j.rse.2013.10.008

Pemerintah Provinsi Papua, 2006. Pemerintah Provinsi Papua. URL https://www.papua.go.id/index.html (accessed 4.30.20).

Schindler, K., 2012. an Overview and Comparison of Smooth Labeling Methods for Land-Cover Classification. IEEE Trans. Geosci. Remote Sens. 50, 4534-4545.

Sulaeman, A., Suhartanto, E., 2017. Analisis Genangan Banjir akibat Luapan Bengawan Solo untuk Mendukung Peta Risiko Bencana Banjir di Kabupaten Bojonegoro. J. Tek. Pengair. 8 , 146-157.

The Charter, 2019. Flood in Indonesia - Activations International Disasters Charter. URL https://disasterscharter.org/web/guest/activations/-/article/floodin-indonesia-activation-600- (accessed 4.30.20).

van Rijsbergen, C.J., 1979. Information Retrieval, 2nd ed. London: Butterworths 